\title{
Assessing absentmindedness: Prospective memory complaint and impairment in middle-aged adults
}

\author{
TIMO MÄNTYLÄ \\ Umeå University, Umeå, Sweden
}

\begin{abstract}
In two experiments, metamemorial differences between prospective and retrospectivememory performance were examined. Participants in Experiment 1 were recruited through newspaper advertisements and comprised middle-aged women who experienced exceptional problems in prospective remembering. Experiment 2 involved self-reporters and nonreporters of retrospective memory problems, who were selected from a large population-based sample of middle-aged adults. In both experiments, memory performance was assessed by using a variety of tasks, including five retrospective memory tasks and three prospective memory tasks that varied in level of realism and retrieval support. In both experiments, there were selective differences in memory performance, so that participants who experienced (retrospective or prospective) memory problems showed impaired performance in prospective, but not in retrospective, memory tasks. These findings suggest that memory for future intentions provides a more sensitive task criterion than does memory for past events for assessing individual differences in self-reports of episodic memory problems. Task-specific differences in reliance on frontally mediated executive processes might underlie these differences.
\end{abstract}

Everyday mnemonic functioning is determined by the individual's awareness and knowledge of his or her own mnemonic competence. For instance, whether people should spend time using an external mnemonic device, such as a notebook, depends on efficiently functioning metamemory (Intons-Peterson, 1993). Yet, in past research, a weak relation has been observed between selfreports of everyday memory functioning and actual performance of laboratory-based tests of episodic memory (e.g., Herrmann, 1982; Larrabee \& Levin, 1986; Scogin, 1985; Sunderland, Watts, Baddeley, \& Harris, 1986; West, Boatwright, \& Schleser, 1984; see also Dixon \& Hultsch, 1983; Riege, 1982; Zelinski, Gilewski, \& Thompson, 1980, for exceptions).

One reason for these discrepancies is that self-reports of memory problems reflect differences in lifestyle, social expectations, and emotional states (Hertzog, Dixon, \& Hultsch, 1990; Rabbitt \& Abson, 1990). Observed discrepancies might also be related to the limitations of criterion variables. As Kausler (1991) noted in his review of adult age differences in metamemorial functions, "the construction of memory questionnaires has been guided by an empirical approach, rather than by explicit memory theory, such that scores may be derived separately for

This research was supported by the Swedish Council for Research in the Humanities and Social Sciences. I am grateful to Maria Nordin, Gunilla Smedberg-Åman, and Pia Tuttle for their assistance in data collection. Correspondence concerning this article should be addressed to T. Mäntylä, Department of Psychology, Umeå University, S-90187 Umeå, Sweden (e-mail: timo.mäntylä@psy.umu.se). memory functioning as it involves effortful episodic memory, automatic episodic memory, prospective memory, and lexical memory" (p. 541).

In this study, the relation between subjective and objective memory performance was examined by focusing on a specific instance of episodic memory-namely, prospective remembering (see Brandimonte, Einstein, \& McDaniel, 1996, for an overview). The present study was based on the notion that the relation between subjective and objective memory performance might be more apparent in prospective memory tasks than in retrospective (overall) memory tasks, because memory for future intentions reflects complex mnemonic activities, including response inhibition, task switching, monitoring, and updating of intentions and plans (Bisiacchi, 1996; Burgess, Veitch, de Lacy Costello, \& Shallice, 2000; Glisky, 1996; McDaniel, Glisky, Rubin, Guynn, \& Routhieaux, 1999; see also Shallice \& Burgess, 1991; Stuss \& Benson, 1987).

The task characteristics mentioned above might have metamemorial consequences, so that people are particularly aware of their own mnemonic competence in futureoriented tasks. Furthermore, people might be better calibrated for prospective than for retrospective memory tasks because to forget one's intentions can have serious social and practical consequences in everyday life (Marsh, Hicks, \& Landau, 1998; Reason, 1990; Terry, 1988).

A possibility also exists that metamemorial differences between prospective and retrospective memory reflect differences in criterion sensitivity, rather than in the nature of subjective awareness. Given that most prospective memory tasks require not only remembering when 
but also what should be remembered, self-reports of prospective and retrospective memory might be highly correlated, so that people who consider themselves "absentminded" also report problems in memory for past events, and vice versa. From that perspective, complaints of prospective memory problems are not qualitatively different from those of retrospective memory, but prospective memory tasks provide a more sensitive criterion for detecting actual impairments in episodic memory performance. Consistent with this notion, prospective memory has been considered to be more vulnerable than retrospective memory to the effect of cognitive impairment in dementia (Huppert \& Beardsall, 1993). Furthermore, age-related differences in episodic memory performance are typically accentuated in tasks that are assumed to depend on executive functioning (Cohen \& Faulkner, 1989; Craik, Morris, Morris, \& Loewen, 1990; Erngrund, Mäntylä, \& Nilsson, 1996; Hashtroudi, Johnson, \& Chrosniak, 1989; McIntyre \& Craik, 1987).

In the present study, subjective and objective memory performance was examined in middle-aged, rather than older, adults. One reason for this specific focus was that the effects of individual and age-specific differences in lifestyle and social expectations would be reduced by studying healthy, middle-aged adults. Furthermore, research on middle-aged adults' metacognitive functions has been a rather neglected area in the memory literature, because the primary interest of past research has been on children's and elderly adults' metamemorial functioning.

Two complementary approaches for examining the validity of subjective memory complaints in prospective memory were used. Experiment 1 was focused on individuals who experienced exceptional problems in prospective remembering and involved healthy, middle-aged women who were recruited through newspaper advertisements. These individuals considered themselves to be exceptionally absentminded in that they frequently forgot important everyday activities, such as planned appointments and meetings, although they did not experience similar problems in other cognitive tasks, such as memory for past events. These self-reporters of prospective memory problems were compared with a similar group of nonreporters, who did not acknowledge having problems in episodic remembering.

Experiment 2 was based on a more traditional recruitment procedure by involving a large, population-based sample of middle-aged adults. On the basis of data from a standardized memory questionnaire, the participants were divided into groups of self-reporters and nonreporters of retrospective and prospective memory problems, respectively, and episodic memory performance was assessed by a series of retrospective and prospective memory tasks.

\section{EXPERIMENT 1}

Experiment 1 comprised three main phases and lasted for a period of 1 year. The first phase comprised a labo- ratory session, during which the participants completed a series of cognitive tasks and questionnaires related to lifestyle and experienced memory problems. The cognitive tasks of the laboratory session included four retrospective memory tasks and two laboratory-based tasks of prospective memory. After performing these and other cognitive tasks (verbal fluency and metamemory judgment), the participants carried out a naturalistic prospective memory task, which constituted the second phase of the study. During this field session, the participants were supposed to remember to make a series of telephone calls (cf. Maylor, 1990; Moscovitch, 1982).

The final phase of the study was completed 1 year after the laboratory and field sessions. One important objective of the follow-up phase was to examine whether complaints of prospective memory would be reported even 1 year later. Specifically, prospective memory complaints might be related to contextual and temporary factors during the test period, so that the self-reporters would experience similar memory problems 1 year later. This issue is also important because few studies have examined longitudinal changes in (overall) memory complaints (but see Smith, Ivnik, Malec, \& Tangalos, 1993; Taylor, Miller, \& Tinklenberg, 1992), and past research concerning the stability of more specific memory complaints, such as remembering future intentions, has been virtually nonexistent.

One central objective of this study was to examine the relation between objective and subjective memory performance under conditions in which the effects of depression and anxiety were minimized. Specifically, because a stronger relation has been found between subjective memory assessments and depression than with actual (retrospective) memory performance (e.g., Kahn, Zarit, Hilbert, \& Niederehe, 1975; McGlone et al., 1990; Poinrenaud, Malbezin, \& Guez, 1989), only individuals who were considered to be free from depressive symptoms participated in the study. Also, only healthy middleaged individuals were included, because past research has found that not only symptoms of depression, but also somatic health problems are associated with higher levels of memory complaints (Cutler \& Grams, 1988; Tun, Perlmutter, Russo, \& Nathan, 1987).

\section{Method}

Participants. During the recruitment phase, potential participants were recruited through newspaper advertisements. These advertisements appeared four times in a local newspaper during a 2-week period, and stated: "Are you absentminded? Do you have problems in remembering to remember?" The announcement included examples of prospective memory problems in everyday situations (e.g., forgetting appointments) and explained that the study was focused on middle-aged persons with exceptional difficulties in prospective remembering. Ninety-one people (73 women and 18 men) responded to the advertisement during a 3 -week period (after which no additional participants were included).

Next, a psychologist interviewed each respondent by asking questions about the individual's demographic background, type of memory problems, mental health, and general well-being. The objective of the interview was to identify and exclude individuals who exhibited symptoms of psychological distress, such as sleep disor- 
Table 1

Experiment 1: Participants' Background Characteristics (With Standard Deviations in Parentheses)

\begin{tabular}{lcc}
\hline \multicolumn{1}{c}{ Measure } & $\begin{array}{c}\text { Self-Reporters } \\
(n=40)\end{array}$ & $\begin{array}{c}\text { Nonreporters } \\
(n=32)\end{array}$ \\
\hline Age & $42.9(6.7)$ & $44.7(6.5)$ \\
Years of education & $13.7(3.3)$ & $14.6(4.7)$ \\
Marital status & $.60 / .19 / .21$ & $.77 / .13 / .10$ \\
Living arrangement & $.43 / .57$ & $.60 / .40$ \\
Stress level & 5.89 & 6.12 \\
Fluency-A & $14.1(4.4)$ & $14.7(4.6)$ \\
Fluency-M5 & $6.1(2.8)$ & $7.2(3.2)$ \\
\hline
\end{tabular}

Note-Marital status: married/nonmarried/divorced participants. Living arrangement: apartment/own house. Stress level: self-ratings on a 10-point scale, with $\max 10=$ very stressful. Fluency-A: words with $\mathrm{A}$ as the initial letter. Fluency-M5: 5-letter words with M as the initial letter.

ders, depression, and anxiety. Participants were included in the study if they were between the ages of 35 and 55 years, had fulltime employment, and had no severe sensory handicaps or health problems, including psychiatric disorders and alcohol or drug abuse. Forty individuals were excluded, with similar distributions of reasons for males and females (primarily due to health problems, symptoms of psychological distress, and employment status). Because the final sample of males was reduced to 11 individuals, only female participants were included in the study.

The final sample of self-reporters comprised 40 women between the ages of 35 and 55 years. Of the 40 female self-reporters, 4 individuals were unable to complete the whole study, including the followup phase. In addition to the self-reporters, a group of nonreporters participated in the study. They were from the same population as the self-reporters - namely, middle-aged women living in Umeå, which is a medium-size town (population of 100,000). The comparison group was recruited by sending facsimiles to different work places explaining the general aims of the study and that it focused on 35to 55-year-old women who did not experience any particular memory problems. They were explicitly informed that the study concerned individual differences in absentmindedness and that they should not have experienced any particular problems in memory for future intentions or past events. Thirty-two individuals volunteered to participate in the study. Six nonreporters were excluded from the final sample by using the same criteria as for the self-reporters. Both the self-reporters and nonreporters were paid the equivalent of $\$ 20$ for their participation.

As can be seen in Table 1, the self-reporters and nonreporters were comparable in terms of age, educational attainment, marital status, living arrangements, and subjective stress level. The questionnaire data also showed (although this is not summarized in Table 1) that the self-reporters and nonreporters were comparable with respect to self-reported health status, number of children, type of leisure activities, and type of occupation.

Procedure. Before arriving at the laboratory, each participant had completed a demographic questionnaire and a memory inventory (Compensation Questionnaire; Dixon \& Bäckman, 1992). During the first phase of this session, the experimenter provided general information about the tasks and discussed the forms and questionnaires that the participant had completed at home. The participants were asked to "remind the experimenter to sign a piece of paper when the session was completed." In this prospective memory task, referred to as the reminding task, demands for self-initiated retrieval were varied in three successive test conditions (see also Mäntylä \& Nilsson, 1997). During the first test phase, which took place $1 \mathrm{~h}$ after the test instructions, the requirements for self-initiated retrieval were maximal, in the sense that the participants were supposed to remember to remind the experimenter in the absence of explicit cues. If a participant failed to perform the planned action within a time limit of $15 \mathrm{sec}$, the experimenter asked in the second test phase "whether there was something else to be done." Finally, in the third successive test phase, in which the requirements for selfinitiation were minimal, the experimenter asked the participant what she was supposed to remember to remember (i.e., retrospective memory for the content of the reminding task).

After the reminding instructions, the participants studied 16 color prints of faces of 10-year-old children, with an equal number of boys and girls. A fictitious first and family name was written below each face. Two equivalent sets of pictures were used, with one set of items serving as targets and the other set as distractors for half of the participants, and vice versa for the remaining participants. The experimenter presented each stimulus picture at the rate of $8 \mathrm{sec}$ per item, and the participants were instructed to remember the faces and the family names for a later recognition test. After a 45-min interval, the participants completed a face-recognition test, in which the 12 target faces (two primacy and two recency items were excluded) were presented along with 12 nonstudied faces as distractors. Each test item was presented in a random order, at the rate of $15 \mathrm{sec}$ per item, during which the participants made a yes-no recognition judgment. In the subsequent name recognition test, the participants were presented each studied face along with four different combinations of first and family names and were asked to select the combination that they believed had been presented earlier along with the face.

In the next task, referred to as the word recall task, the participants heard a list of 25 common, unrelated nouns. The study words were presented at the rate of $3 \mathrm{sec}$ per item, along with instructions to learn these words for an immediate free recall test. Before the study phase, the participants completed an on-line recall efficacy task. In this metamemory task, the participants estimated their expected free recall performance by indicating a number between 0 and 25 $(25=$ maximum recall $)$.

In the second laboratory-based prospective memory task, referred to as the association task, the participants were given a background task in which they heard a list of 120 words, presented at the rate of $8 \mathrm{sec}$ per item. They were asked to describe the meaning of each presented word by generating one association that came to mind. The participants were instructed to write down their associations in a booklet, with one association on each page of the booklet (see also Mäntylä, 1986). The participants were not informed of the subsequent (retrospective) memory test, in which they were given their own associations as cues.

Parallel with the study phase of the free-association task, the participants were instructed to write a cross on the corresponding page of the booklet whenever they heard an instance of any of the four following categories: liquids, parts of the human body, vehicles, and parts of a building. Eight prospective targets were included in the study list, two from each category. They were randomly distributed in the list, with the restriction that the interitem interval was at least eight nontargets and two consecutive targets belonged to different semantic categories. Furthermore, requirements for self-initiated retrieval were manipulated by varying item typicality. Half of the target items were typical members of a given semantic category; the remaining targets were atypical category instances. Thus, the participants were supposed to monitor for four different target categories, and within each task criterion, one of the two targets was a peripheral instance of a given semantic category. The target items that were peripheral members of a given category were assumed to require a higher degree of self-initiated retrieval operations than were the targets that were closely related to the task criterion (e.g., milk vs. ink as a member of the category liquids). In other words, the demands for self-initiated retrieval operations were expected to increase as a function of decreasing item typicality because, relative to the semantic category criterion, atypical items are more difficult to identify as prospective memory targets than are typical items (see also Mäntylä, 1994). 
Following the face and name recognition tasks, the participants completed a cued recall task by using their own associations as cues. Specifically, the participants were instructed to recall the words to which they had generated the associations. To avoid practice and recency effects, associations corresponding to the eight prospective targets and the first and last 30 items of the 120-item study list were excluded from the cued recall test. The order of presentation of test cues was random and different for each participant. Recall rate was subject paced, and the test phase took about $10 \mathrm{~min}$ to complete.

The final laboratory task comprised two measures of word fluency. The participants generated as many words as possible during a period of 1 min for (1) words with the initial letter A, and (2) five-letter words with the initial letter M. After completing the fluency tasks, the experimenter informed the participants that "we have now completed all the tasks." Following this announcement, the participants were supposed to remind the experimenter that a document should be signed.

The third prospective memory task, referred to as the telephone task, was "naturalistic," in that it was carried out in an everyday setting during a period of 10 days. Before leaving the laboratory, the participants were asked to telephone the experimenter 7 and 10 days later. Specifically, the experimenter informed the participants that they were supposed to make two telephone calls during a 10-day period and that these phone calls should be made during exact times of each day. The experimenter's telephone number, dates, and corresponding call-in times for both days were printed on an $8 \times 5 \mathrm{~cm}$ piece of paper. The experimenter instructed each participant to use that note as a reminder during the forthcoming test period. Call-in times were between 9:00 and 12:00 a.m. and between 1:00 and 5:00 p.m., with an equal number of times before and after noon. For each participant, one of the call-in times occurred during the morning session, and the other time during the afternoon session. Furthermore, one of the call-in times was on the exact hour (e.g., 11:00 a.m.), whereas the other time was 15 min off the hour (e.g., 10:45 a.m.). The order of session and type of call-in time were counterbalanced across conditions. When telephoning, the participants reported their names and telephone numbers to an operator (at a local answering service company), who also registered exact call-in times. About 4-6h after the second call-in time (and in some cases, during the following day), the experimenter contacted the participants and asked them to describe their behavior during the test period. Specifically, each participant was asked to clarify her strategies for remembering to make the telephone calls and, if necessary, to describe the circumstances related to her prospective memory failures.

One year after the test sessions, the experimenter interviewed the self-reporters and nonreporters in a follow-up session, during which the participants answered standardized questions related to their motivation to participate in the study and current memory problems. Furthermore, the participants completed the Swedish version of the Prospective and Retrospective Memory Questionnaire (Crawford, Smith, Maylor, Della Sala, \& Logie, in press; Maylor, Logie, Della Sala, \& Smith, 1996).

\section{Results and Discussion}

Assessment of memory complaints. As mentioned earlier, the participants completed two memory inventories at home-namely, the Compensation Questionnaire (CQ) and the Prospective and Retrospective Memory Questionnaire (PRMQ), which was also completed during the follow-up session. The former inventory was designed to provide systematic information about individuals' efforts to compensate for memory failures in everyday situations. The CQ reflects six dimensions of compensatory mechanisms, including (1) use of external aids, such as notes and calendars, (2) use of internal mnemonics, such as imagery, (3) investment of more time, such as reading passages more slowly, (4) investment of more effort, such as concentrating and trying harder, (5) reliance on other people as memory aids, such as asking a friend, and (6) relaxation of the criteria of successful performance, such as deciding that one's expectations should be adjusted to match one's current skills. Furthermore, the CQ provides information about any changes experienced in each of these six dimensions. The participants rated their reliance on different compensatory strategies by using a 5 -point scale, with $1=$ very often and $5=$ never.

The CQ data indicated that the self-reporters reported a higher degree of reliance on internal $(M=2.99)$ and external (1.74) aids as well as on other people (3.05) than did the nonreporters $(3.30,2.18$, and 3.92, respectively; all $p \mathrm{~s}<.05)$. Furthermore, the self-reporters invested more time $(2.62$ vs. $3.04 ; p<.07)$ and effort $(2.26$ vs. $2.93 ; p<.01)$ than did the self-reporters, but they did not report using a more relaxed criterion of success than the nonreporters (2.91 vs. 3.22 ). These data suggest that the self-reporters had knowledge of different compensatory strategies, and that they seemed to rely on these strategies more than the nonreporters did. The CQ data also indicated that the self-reporters' compensatory behavior had accentuated during the last 5 years.

The PRMQ was designed to assess both retrospective and prospective memory complaints and comprises eight questions related to problems in prospective remembering (e.g., "Do you decide to do something in a few minutes' time and then forget to do it?") and eight retrospective memory questions (e.g., "Do you fail to recognize a place that you have visited before?"). Each item was rated on a 5-point scale, with $4=$ very often and $0=$ never. Crawford et al. (2001) examined the latent structure of the PRMQ and found that the model with the best fit had a tripartite structure and consisted of a general memory factor plus orthogonal specific factors of prospective and retrospective memory. The reliabilities of the total scale and the prospective and retrospective scales were acceptable (Cronbach's $\alpha$ was $0.89,0.84$, and 0.80 , respectively).

The PRMQ data showed that the self-reporters' mean ratings of the retrospective (19.85 vs. 15.73) and prospective (24.71 vs. 18.87$)$ items were greater than those of the nonreporters and that the group difference was accentuated for the latter item type. A 2 (group) $\times 2$ (item type) mixed factors analysis of variance (ANOVA) confirmed this observation by yielding significant main effects of group $\left[F(1,57)=18.38, M S_{\mathrm{e}}=33.48, p<.01\right]$ and item type $\left[F(1,57)=65.07, M S_{\mathrm{e}}=33.48, p<.01\right]$, as well as an interaction between these factors $[F(1,57)=$ 4.94, $\left.M S_{\mathrm{e}}=25.76, p<.05\right]$.

The final phase of the study was completed 1 year after the laboratory and field sessions and included an interview in which the self-reporters expressed their current experience of memory problems. These data indicated that a majority of the self-reporters still considered themselves to be having serious problems in prospective 
Table 2

Experiment 1: Retrospective Memory Performance

\begin{tabular}{llllll}
\hline & \multicolumn{2}{c}{ Self-Reporters } & & \multicolumn{2}{c}{ Nonreporters } \\
\cline { 2 - 3 } \cline { 5 - 6 } \multicolumn{1}{c}{ Measure } & $M$ & $S D$ & & $M$ & $S D$ \\
\hline Observed word recall & .35 & .08 & & .36 & .08 \\
Expected word recall & .40 & .13 & .35 & .10 \\
Cued recall & .64 & .14 & .65 & .19 \\
Face recognition (hits-FA) & .66 & .14 & .61 & .16 \\
Name recognition (hits-FA) & .67 & .17 & .70 & .18 \\
\hline
\end{tabular}

remembering. Specifically, $81 \%$ of the self-reporters and $76 \%$ of the nonreporters considered that their mnemonic competence was the same as it was 1 year ago. Of the remaining self-reporters, $11 \%$ felt that their memory was "somewhat better" and $8 \%$ "somewhat worse." Thus, a great majority of the self-reporters still experienced similar or worse memory problems than they did 1 year previously.

Retrospective memory performance. Memory for past events was assessed by using four tasks - namely, free recall of words, cued recall of words (with participants' own associations as cues), face recognition, and name recognition. As can be seen in Table 2, the overall pattern of these data indicates that the self-reporters' retrospective memory performance was comparable with that of the nonreporters. Table 2 also shows that the self-reporters' expected free recall performance was somewhat (but not significantly) greater than that of the nonreporters. If anything, these data might indicate that the self-reporters were overestimating their actual capacity for word recall.

Taken together, the data from the retrospective memory tasks suggest that the self-reporters did not have actual problems in remembering past events. Instead, their retrospective memory performance, measured in a variety of laboratory tasks, was comparable with those of the nonreporters. These data are consistent with past research in that they showed a modest correlation between subjective and objective performance in retrospective memory. Specifically, as indicated by the PRMQ data, the self-reporters reported a higher frequency of retrospective memory problems than did the nonreporters. In spite of these differences in subjective complaints, there were no group differences in actual retrospective memory performance.

Prospective memory performance. In the reminding task, successful performance was observed when the participant reminded the experimenter to sign a paper within $15 \mathrm{sec}$ after the experimenter had informed them that the session was completed. A response was categorized as uncued retrieval if it was given within $15 \mathrm{sec}$ and the action was carried out correctly (i.e., the experimenter was reminded to sign a paper). Furthermore, if a participant failed in the uncued test but responded correctly when the experimenter (after $15 \mathrm{sec}$ ) asked, "whether there was something else to be done," the response was considered as cued retrieval. Finally, a response was categorized as content retrieval if the participant failed in cued recall but correctly reported the to-be-performed action.

Table 3 summarizes the response distribution as a function of group and successive retrieval condition. To clarify these data, the first column of the table shows that $63 \%$ of the self-reporters were successful in the uncued retrieval condition and that the recall rate increased to $83 \%$ and $92 \%$ when the successive cued-retrieval and content-retrieval conditions, respectively, were taken into consideration. What is readily apparent in Table 3 is that, compared with the nonreporters, the self-reporters showed lower levels of performance in the uncued recall condition. Furthermore, the data indicate that the provision of retrieval support increased performance for both groups, with no substantial differences in performance between them. Finally, the content recall data suggest that potential group differences in uncued performance were not due to failures in remembering the retrospective memory component of the task (i.e., remembering what to do). Statistical analyses (with a Pearson chi-square test) revealed that the $10 \%$ difference in success rate between the self-reporters and nonreporters was marginally significant $(p=.07)$ in the uncued condition. These data indicate that the self-reporters had somewhat greater difficulty in the reminding task than did the nonreporters, but this difference was eliminated when more explicit cues were provided at test.

Performance in the association task was based on the eight targets, with the maximum of four responses for each of the two levels of item typicality. A response was scored as correct if a participant wrote a cross on the target page of the booklet. With respect to error analyses, the proportion of intrusions (i.e., responses to nontarget items) was less than $2 \%$ for both groups.

The lower section of Table 3 summarizes prospective memory performance in the association task as a function of group and item typicality. These data show minimal group differences when typical category instances were presented as cues (e.g., milk-LIQUID). However, the difference between the two groups was $15 \%$ for atypical category instances (e.g., sweat-LIQUID). A 2 (group) $\times 2$ (item typicality) mixed-factors ANOVA, with repeated measures on the last variable, revealed a significant main effect of typicality $\left[F(1,56)=18.65, M S_{\mathrm{e}}=0.22, p<\right.$ $.01]$ and an interaction between group and item typicality $\left[F(1,56)=4.61, M S_{\mathrm{e}}=0.22, p<.05\right]$, but no main effect of group $(F<1)$. A test of simple effects revealed that the group difference was significant for atypical $(p<.05)$ but not for typical items $(p>.20)$.

In the telephone task, successful performance was scored by using three successive response criteria. Namely, a response was considered as successful if it was given (1) within $5 \mathrm{~min}$ from the target time, (2) within $15 \mathrm{~min}$ from the target time, or (3) more than 15 min from the target time. Table 5 summarizes these data as a function of group and target day, with Day 1 and Day 2 referring to the 7-day and 10-day retention intervals, respectively.

As can be seen in the upper section of Table 4, the two groups showed similar Day 1 success rates for all three 
Table 3

Experiment 1: Laboratory-Based Prospective Memory Performance

\begin{tabular}{|c|c|c|c|c|}
\hline \multirow[b]{2}{*}{ Memory Task } & \multicolumn{2}{|c|}{ Self-Reporters } & \multicolumn{2}{|c|}{ Nonreporters } \\
\hline & $M$ & $S D$ & $M$ & $S D$ \\
\hline \multicolumn{5}{|l|}{ Reminding Task } \\
\hline Uncued & .63 & .08 & .73 & .09 \\
\hline Cued & .83 & .06 & .86 & .07 \\
\hline Content & .92 & .05 & .91 & .06 \\
\hline \multicolumn{5}{|l|}{ Association Task } \\
\hline Typical targets & .63 & .34 & .60 & .31 \\
\hline Atypical targets & .36 & .28 & .51 & .23 \\
\hline
\end{tabular}

scoring criteria $\left(\chi^{2}<1\right)$, with only $14 \%$ of the selfreporters and $23 \%$ of the nonreporters failing to make the first telephone call. One reason for this (nonsignificant) difference in the failure rate was that more nonreporters than self-reporters had valid excuses for their "failures" (see below). Furthermore, as can be seen in Table 4, the numeric difference in failure rate was related to the fact that the self-reporters made their phone calls relatively late (i.e., $>15 \mathrm{~min}$ ). Thus, the observed differences in failure rate might have been mediated by differences in response strategies, so that the self-reporters used a more liberal criterion than did the nonreporters when making (late) telephone calls.

A rather different pattern of results can be seen in the Day 2 data. Specifically, $50 \%$ of the self-reporters forgot to make a call during the 2 nd target day, whereas the corresponding failure rate for the nonreporters was only $24 \%\left(\chi^{2}=4.24, p<.05\right)$. Thus, although the two groups were equally successful at Day 1 , the difference in failure rate was 26\% at Day 2, favoring the nonreporters (who showed the same pattern of performance for both responses). Speculatively, transient motivational effects might, in part, explain this pattern of results. Most of the self-reporters were highly motivated to participate in the study and were probably even more motivated to perform well in the memory tasks than were the nonreporters. These differences in motivation might have contributed to the self-reporters' good Day 1 performance. However, successful task completion during Day 1 could have reduced these motivational effects (cf. Goschke \& Kuhl, 1993; Mäntylä \& Sgaramella, 1997; Marsh, Hicks, \& Bink, 1998), producing a significant decrement in Day 2 performance.

To obtain additional information about the participants' behavior during the telephone task, the experimenter contacted each individual after the task was completed. During that (telephone) interview the experimenter asked each participant how she had remembered to make the telephone calls, or in the case of a failure, why the participant had forgotten to make the call(s). Reasons for telephoning late or not at all were categorized (by an independent rater) either as valid excuses or as memory failures. The proportion of valid excuses was greater for the nonreporters (.30) than for the self-reporters (.05). In addition to valid excuses, four reasons of memory fail- ures were identified: (1) absorbed (e.g., busy with other things), (2) distracted (e.g., unexpected break in routine), (3) reminder failure (e.g., lost or misplaced reminder), and (4) no specific reason. These response categories corresponded to those reported by Maylor (1990), who identified six reasons for failures (including illness and anxiety of something and fell asleep or overslept). Table 5 presents the distribution of reasons given for the memory failures that occurred during Day 2 of the telephone task (all of the Day 1 failures were attributed to distraction).

Table 5 shows that a lost or misplaced reminder was the primary source for a failure among the self-reporters, whereas only $12 \%$ of the nonreporters attributed their behavior to external failures. Although these data should be interpreted with caution, they are consistent with the CQ data and indicate that the self-reporters were more dependent on external support (i.e., notes and reminders) than were the nonreporters. Speculatively, the selfreporters' dependency on external aids might have increased the incidence of lost reminder as a subjective reason for failures in the telephone task.

\section{EXPERIMENT 2}

Experiment 1 showed selective differences in episodic memory performance, so that the self-reporters' retrospective memory performance was comparable with that of the nonreporters, whereas their prospective memory performance was impaired in both the laboratory-based and the naturalistic tasks. This pattern of results supports the notion that the relation between subjective and objective memory performance is more consistent in prospective memory tasks than in retrospective (overall) memory tasks. However, because only self-reporters of prospective memory problems were included in Experiment 1, these findings do not justify the conclusion that there are metamemorial differences between prospective and retrospective memory.

Instead, the results of Experiment 1 might suggest that that the relation between subjective and objective memory performance is more apparent when self-reports of memory problems refer to a relatively limited set of everyday tasks. Thus, as a complementary account, specificity of memory complaint, rather than the future-

Table 4

Experiment 1: Prospective Memory Performance in the Telephone Task

\begin{tabular}{llllll}
\hline & \multicolumn{2}{c}{ Self-Reporters } & & \multicolumn{2}{c}{ Nonreporters } \\
\cline { 2 - 3 } \cline { 5 - 6 } Measure & $M$ & $S D$ & & $M$ & $S D$ \\
\hline Day 1 Success Rate & & & & \\
$\quad \leq 5 \mathrm{~min}$ & .58 & .07 & .59 & .08 \\
$\leq 15 \mathrm{~min}$ & .67 & .08 & .64 & .09 \\
$>15 \mathrm{~min}$ & .86 & .09 & .77 & .10 \\
Day 2 Success Rate & & & & \\
$\quad \leq 5 \mathrm{~min}$ & .36 & .08 & .59 & .10 \\
$\leq 15 \mathrm{~min}$ & .44 & .08 & .62 & .10 \\
$>15 \mathrm{~min}$ & .50 & .08 & .77 & .08 \\
\hline
\end{tabular}


Table 5

Experiment 1: Attributions of Memory Failures in the Telephone Task

\begin{tabular}{lcc}
\hline Reason for Failure & Self-Reporters & Nonreporters \\
\hline Absorbed & .14 & .12 \\
Distracted & .10 & .25 \\
Lost reminder & .43 & .13 \\
No reason & .33 & .50 \\
\hline
\end{tabular}

oriented nature, or type of memory complaint, might have determined the observed relation between objective and subjective memory performance.

A recent study by Hertzog, Park, Morell, and Martin (2000; see also Park et al., 1999) indicated that adults' self-reports of episodic memory problems are valid when they focus directly on specific memory-related behavior in everyday situations. In their study, adults between the ages of 35 and 85 years completed a memory questionnaire and an extensive set of cognitive tasks, including measures of free recall of word lists and prospective memory. In the latter task, the participants were to make seven phone calls to an answering service over 7 days. During an interview about their prescribed medications, the participants (who were patients with rheumatoid arthritis) also reported whether they were having problems remembering to take their medication as prescribed. Their medication adherence at home was then monitored for a month by using pill bottles with microelectronic caps.

Hertzog et al. (2000) found that performance in cognitive tasks correlated with memory complaints, but not with problems in remembering to take medication. Conversely, reported problems with medication during the interview had good predictive validity for subsequent adherence problems, but not for cognitive tasks, including a measure of prospective memory (i.e., the telephone task). Hertzog et al. (2000) interpreted these results in terms of a behavioral specificity hypothesis, which states that self-reported complaints of (prospective and retrospective) memory are valid to the extent that questions are specific to the behaviors in question (i.e., people complaining of difficulties in remembering to take medication show actual problems in medication adherence, but not in remembering to make phone calls in everyday contexts, and vice versa).

Although the findings of Hertzog et al. (2000) were consistent with the behavioral specificity (rather than the domain specificity) hypothesis, the interpretation of these results is complicated by the fact that medication adherence was the only behaviorally specific criterion variable (for a group of rheumatoid patients) and that participants' nonspecific prospective memory performance was based on the telephone task (which might have weaknesses in experimental control).

Another reasonable interpretation of the results in Experiment 1 is that they reflected differences in criterion tasks, rather than in self-reports, per se. Although most people might be aware of the distinction between prospec- tive and retrospective memory, a possibility exists that there are no qualitative differences in subjective reports of prospective and retrospective memory problems. The PRMQ data of Experiment 1 support this interpretation, in that the self-reporters' mean ratings of both types of memory tasks were greater than those of the nonreporters (see also Crawford et al., in press, for more formal analyses of the PRMQ).

Instead of reflecting the differences in subjective reports of prospective and retrospective memory problems, the results of Experiment 1 might reflect differences in criterion tasks, so that prospective memory tasks provide a more sensitive task criterion than do retrospective memory tasks. Following this sensitivity notion, individuals who are self-reporters of prospective memory problems would also experience problems in retrospective memory, and vice versa. Furthermore, these self-reporters of (prospective and retrospective) memory problems would show impaired performance in prospective, but not necessarily in retrospective, memory tasks.

To contrast these alternative interpretations, Experiment 2 involved a large number of middle-aged adults, who were categorized as self-reporters and nonreporters of prospective and retrospective memory problems, respectively, and their actual memory performance was assessed by using a series of retrospective and prospective memory tasks. On the basis of the reasoning outlined above, a finding showing differences in retrospective memory performance between self-reporters and nonreporters of retrospective memory would indicate that (domain) specificity between objective and subjective memory performance, rather than the prospective nature of the criterion task, is critical for predictive validity. Alternatively, a pattern of results showing that self-reporters of retrospective memory problems also demonstrate impaired performance in prospective, rather than in retrospective, memory performance would support the notion that measures of prospective memory provide a more sensitive task criterion than do retrospective memory tasks.

\section{Method}

Participants and Procedure. The participants in Experiment 2 were recruited from a population-based sample of healthy adults between the ages of 35 and 55 years. The comparison data emanate from the third wave of data collection of the Betula project, which is a longitudinal study on memory, health, and aging (see Nilsson et al., 1997). During that session, a group of middle-aged and older adults $(N=500)$ was tested for the first time. The procedure of the third test session was the same as that of the first two sessions of the Betula project, except that the PRMQ was used to assess participants' self-reports of memory problems. Excluding the older individuals, the participants in Experiment 2 comprised 200 middleaged adults between 35 and 55 years, with an equal number of males and females.

Prospective memory was assessed by using the same reminding task as in Experiment 1, so that each individually tested participant was asked to remind the experimenter to "sign a piece of paper when I tell you that we have finished the session." However, in contrast to Experiment 1, the participants were familiar with this pro- 
Table 6

Experiment 2: Simple Correlations of Memory Measures

\begin{tabular}{llccccc}
\hline \multicolumn{1}{c}{ Variable } & 2 & 3 & 4 & 5 & 6 \\
\hline 1 & Prospective score & $.71^{*}$ & .12 & .10 & .12 & $-.20^{*}$ \\
2 & Retrospective score & - & .01 & .05 & .04 & $-.22^{*}$ \\
3 & Word recall & & - & .14 & $.26^{*}$ & .01 \\
4 & Face recognition & & & - & $.51^{*}$ & .13 \\
5 & Name recognition & & & & - & .02 \\
6 & Reminding task & & & & & - \\
\hline
\end{tabular}

Note-Variables 1-2 refer to the prospective and retrospective subscores of the PRMQ. ${ }^{*} p<.01$.

cedure, because they had signed documents during an earlier session (a medical examination). Furthermore, the retention interval was about 30 min longer here than in Experiment 2 (due to additional tasks included in the Betula project). Thus, the reminding task was even more incidental and naturalistic than that in Experiment 1 . Retrospective memory performance was assessed by using three different measures - namely, word recall, face recognition, and name recognition. These tasks were the same as those in Experiment 1 , except that word recall was based on a 12-item list, presented at the rate of $2 \mathrm{sec}$ per item (see also Nilsson et al., 1997).

Data from the Betula project were also used for assessing the reliability of the prospective and retrospective memory measures included in the present study. These analyses were based on test-retest correlations on the first two test sessions of the project (i.e., a 5-year test-retest interval) and involved a different group of participants than those in Experiment 2. The results of these analyses indicated moderate correlations for all measures, varying between .19 (word recall) and .49 (name recognition). The corresponding correlation for the reminding task was .23, suggesting that the two sets of measures were not differentially reliable. It should be noted that these correlations might underestimate actual reliabilities because there could be substantial individual differences in memory change during the 5-year test-retest interval for persons in the age interval sampled. By using data from the first test session of the Betula project, Nyberg, Bäckman, Erngrund, Olofsson, and Nilsson (1996) reported that the average split-half correlations were .48 for the episodic memory tests and .46 for the semantic memory tests. Another reason for the relatively low (point biserial) correlation for the reminding task is that the target action of the second test session (i.e., to remind the experimenter to mail a letter) was more salient than that of the first test session (see Mäntylä, 2000).

\section{Results and Discussion}

To examine the relation between subjective and objective memory performance, simple correlations were first calculated among each participant's retrospective and prospective scores of the PRMQ and the four measures of memory performance. Concerning the latter measures, the uncued recall data of the reminding task were used for the calculations of (point-biserial) correlations. These analyses were based on the total sample of participants as well as on separate samples of females and males. However, because the three sets of analyses showed the same pattern of results, only the correlations of the total sample are reported here.

The correlation data, which are summarized in Table 6 , show a positive relation between the prospective and retrospective scores of the PRMQ, suggesting that individuals who experienced problems in prospective mem- ory tasks also reported problems in retrospective memory tasks, and vice versa. More important, these analyses showed that neither the prospective nor the retrospective scores of the PRMQ were significantly correlated with any of the three measures of retrospective memory performance. By contrast, both measures of PRMQ (and the total scores) were significantly correlated with performance in the reminding task.

To contrast self-reporters and nonreporters of retrospective and prospective memory, respectively, mediansplit analyses were carried out on the PRMQ data. Specifically, each participant's total score on the eight prospective and retrospective items of the PRMQ were used as a criterion variable for obtaining groups of selfreporters and nonreporters for both task types. Separate median-split analyses showed the same pattern of resultsthat is, the self-reporters' prospective (but not retrospective) memory performance was impaired compared with that of the noncomplainers.

In Table 7, the background characteristics and memory data are summarized for the self-reporters and nonreporters of retrospective memory problems (i.e., the retrospective items of the PRMQ constituted the criterion variable for the median-split analysis). These data showed no reliable differences between the self-reporters and nonreporters in terms of age, level of education, and vocabulary $(p s>.20)$. Furthermore, the results were consistent with the correlation analyses in that the two groups showed comparable levels of retrospective memory performance, measured in terms of word recall, face recognition, and name recognition $(p s>.20)$.

The analyses of the prospective memory data, summarized in Table 7, shows a reliable group difference $\left(\chi^{2}=5.05, p<.05\right)$. That is, $61 \%$ of the nonreporters and $43 \%$ of the self-reporters were successful in the reminding task when no explicit cues were provided at test. As in Experiment 1, the provision of retrieval support in the cued recall condition reduced this difference $\left(\chi^{2}=\right.$ $1.74, p>.05)$, producing only a numerically greater success rate for the nonreporters. It should also be noted that the overall level of performance was lower in Experiment 2 than in Experiment 1. A reasonable explanation for this difference is that in addition to the 30-min longer retention interval, the reminding task was more incidental than that in Experiment 1 (owing to its explicit focus on prospective memory).

Taken together, the results of Experiment 2 replicate the main findings of Experiment 1 by showing selective effects in episodic memory performance, so that individual differences in memory complaints reflect significant differences in prospective, but not in retrospective, memory performance. Furthermore, as in Experiment 1, these data also indicate that complaints of prospective and retrospective memory were correlated, suggesting that self-reports of prospective memory problems are not qualitatively different from those of retrospective memory. The results of Experiment 2 extend these findings, 
Table 7

Experiment 1: Background Characteristics and Memory Performance of Self-Reporters and Nonreporters of Retrospective Memory Problems

\begin{tabular}{lccccc}
\hline & \multicolumn{2}{c}{$\begin{array}{c}\text { Self-Reporters } \\
(n=105)\end{array}$} & & \multicolumn{2}{c}{$\begin{array}{c}\text { Nonreporters } \\
(n=92)\end{array}$} \\
\cline { 2 - 3 } \cline { 5 - 6 } \multicolumn{1}{c}{ Measure } & $M$ & $S D$ & & $M$ & $S D$ \\
\hline Age & 43.4 & 5.6 & & 42.2 & 5.3 \\
Years of education & 13.9 & 3.4 & & 13.8 & 3.5 \\
Vocabulary & 24.0 & 3.4 & & 23.9 & 3.8 \\
PRMQ-prospective & 22.5 & 4.2 & & 16.9 & 3.7 \\
PRMQ-retrospective & 18.6 & 2.2 & & 12.9 & 4.6 \\
Word recall & .41 & .07 & & .42 & .08 \\
Face recognition (Hits-FA) & .64 & .24 & & .63 & .21 \\
Name recognition (Hits-FA) & .63 & .20 & & .61 & .20 \\
Uncued reminding & .43 & .05 & & .61 & .05 \\
Cued reminding & .72 & .05 & .80 & .04 \\
\hline
\end{tabular}

suggesting that the future-oriented nature of the reminding task, rather than its specificity, mediated the predictive validity in the present context.

\section{GENERAL DISCUSSION}

This study examined subjective memory complaints in relation to a relatively well-defined domain of memory tasks-namely, prospective remembering. The relation between subjective and objective memory performance was expected to be more apparent in prospective memory tasks than in retrospective (overall) memory tasks because different forms of executive functionssuch as task switching, monitoring, and updating of intentions and plans-are assumed to be intimately involved in the performance of most prospective memory tasks. These task characteristics were expected to have metamemorial consequences, so that people are particularly aware of their own mnemonic competence in futureoriented tasks, or prospective memory tasks provide a more sensitive task criterion for detecting actual impairments in episodic memory performance.

Experiment 1 was focused on middle-aged women who reported exceptional problems in prospective remembering. Because individual differences in background variables mediate both subjective and objective memory performances, the present study attempted to reduce or eliminate these differences. As a result of an extensive screening, the participants in Experiment 1 represented relatively homogeneous groups of middleaged (rather than elderly) adults. Subsequent analyses of the background data indicated that the self-reporters and nonreporters were comparable in a variety of variables, including age, education, life style, verbal fluency, and mood state. Furthermore, the questionnaire data indicated that the self-reporters' failures in everyday prospective memory tasks were not related to lack of knowledge of different compensatory strategies. Instead, these data indicate that the self-reporters relied more on these strategies than did the nonreporters and that their compensatory behavior had accentuated over the most recent years.
In regard to the validity of prospective memory complaints, in Experiment 1, selective differences were observed in episodic memory performance, so that the selfreporters' retrospective memory performance was comparable with that of the nonreporters, whereas their prospective memory performance was impaired. This pattern of results was obtained by using a variety of memory measures, including retrospective memory for words, names, and faces as well as laboratory-based and naturalistic tasks of prospective memory. In contrast to past research showing moderate or low correlations between subjective and objective memory performance (primarily among elderly adults), the present findings indicate that self-reports reflect actual problems in prospective, but not in retrospective, memory performance.

Because only individuals with self-reported problems in prospective memory were included in Experiment 1, these findings are open to alternative explanations, including the possibility that they reflect differences in specificity of memory complaints. Furthermore, the generality of these results is limited owing to the fact that the participants in Experiment 1 were a rather selected group of self-reporters (who had responded to a newspaper advertisement).

In Experiment 2, a more traditional recruitment procedure was used, which involved a large, population-based sample of middle-aged adults, who were categorized as self-reporters and nonreporters on the basis of memory questionnaire data. The results of Experiment 2 showed that the self-reporters and nonreporters of retrospective memory problems had comparable levels of retrospective memory performance, measured in terms of word recall, face recognition, and name recognition. By contrast, both the correlation and median-split based analyses showed that self-reports of retrospective memory problems reflected actual problems in prospective memory performance.

The results of this study suggest that there are metamemorial differences between prospective and retrospective memory and that these differences reflect the future-oriented nature, rather than specificity, of the memory task. However, it should be noted that the present study was not designed to test the behavioral specificity hypothesis of Hertzog et al. (2000) and that the results of Experiment 2 are inconsistent with the specificity hypothesis at the level of retrospective versus prospective memory (i.e., domain specificity), without excluding the possibility that behavioral specificity contributes to predictive validity.

One reasonable interpretation of the present findings is that prospective memory tasks provide a sensitive criterion for validating self-reports of memory, because memory for future intentions is associated with different forms of frontally mediated executive functions. Although research focusing on the neuropsychological mechanisms of prospective memory is in its infancy, one influential proposal is that, unlike most retrospective memory tasks, prospective memory performance de- 
pends on the prefrontal system and the integrity of the executive systems that these systems subserve (Bisiacchi, 1996; Burgess et al., 2000; Glisky, 1996; McDaniel et al., 1999; see also Stuss \& Benson, 1987). The theoretical assumption of this notion is that different forms of executive functions, such as planning, interruption, response inhibition, self-initiation, and monitoring, are intimately involved in the performance of prospective memory tasks. Past research that has attempted to evaluate this theoretical position is limited, but some studies have reported relations between executive processes and prospective memory (Burgess et al., 2000; McDaniel et al., 1999; see also Bisiacchi, 1996).

It should be noted that the results of Experiment 1 are partly inconsistent with this view, in that the self-reporters and nonreporters showed comparable levels of verbal fluency, although they showed differences in prospective memory performance. There are several possible reasons for this result, including the fact that the range of fluency scores was rather limited in Experiment 1 (possibly because the participants were active and well-educated females).

More consistent support for the executive hypothesis was provided by Mäntylä and Nilsson (1997), who examined prospective memory performance in relation to individual differences in demographic, psychometric, and biological variables. Their study involved a large group of middle-aged and older adults who completed a series of cognitive tasks, including the reminding task used here. They found that verbal fluency was significantly related to prospective memory performance, so that participants with high fluency scores were more successful in the reminding task than those with low scores. Except for age, no other demographic, psychometric, or biological variables were related to the variability in prospective memory performance. Thus, given that fluency is sensitive to executive functioning, the findings of Mäntylä and Nilsson are consistent with the idea that memory for intentions depends on frontally mediated executive functions.

Although the present study involved retrospective and prospective memory tasks that varied in complexity and retrieval demands, a similar pattern of results might be observed by using retrospective tasks that are more dependent on executive functions than the tasks used here. Thus, some tasks of retrospective memory (e.g., source memory) might show a pattern of results corresponding to the three prospective tasks included in this study.

Similarly, prospective memory tasks with low demands on self-initiated (executive) processing might not reflect differences in subjective memory complaints. Consistent with this notion, the results of this study indicate that prospective memory performance varies as a function of retrieval support. In the reminding task, the nonreporters showed better performance than did the selfreporters in the absence of explicit reminders, but this difference was reduced when more explicit reminders were provided. Furthermore, there were no differences between the two groups when highly typical items were presented as cues in the association task. However, when the demands for self-initiated processing were increased in the association task by presenting cues that were more peripherally related to the task criterion, the self-reporters' prospective memory performance was impaired more than that of the nonreporters (see also Mäntylä, 1994, for similar results with younger and older adults).

The present findings suggest that there are metamemorial differences between retrospective and prospective memory tasks and that these effects reflect taskdependent differences in reliance on executive processes. An interesting avenue for future research would be to examine the validity of subjective memory complaints in relation to retrospective and prospective memory tasks that reflect systematic differences in reliance on executive functions. A practical implication of this study is that greater attention should be paid to individual differences in prospective memory performance, including the development and use of memory inventories that emphasize the prospective temporal dimension of episodic remembering.

\section{REFERENCES}

BisiacchI, P. S. (1996). The neuropsychological approach in the study of prospective memory. In M. A. Brandimonte, G. O. Einstein, \& M. A. McDaniel (Eds.), Prospective memory: Theory and applications (pp. 297-317). Hillsdale, NJ: Erlbaum.

Brandimonte, M. A., Einstein, G. O., \& McDaniel, M. A. (Eds.) (1996). Prospective memory: Theory and applications. Hillsdale, NJ: Erlbaum.

Burgess, P. W., Veitch, E., de Lacy Costello, A., \& Shallice, T. (2000). The cognitive and neuroanatomical correlates of multitasking. Neuropsychologia, 38, 848-863.

Cohen, G., \& Faulkner, D. (1989). Age differences in source forgetting: Effects on reality monitoring and on eyewitness testimony. Psychology \& Aging, 4, 10-17.

Craik, F. I. M., Morris, L. W., Morris, R. G., \& Loewen, E. R. (1990). Relations between source amnesia and frontal lobe functioning in older adults. Psychology \& Aging, 5, 148-151.

Crawford, J. R., Smith, G., Maylor, E. A., Della Sala, S., \& Logie, R. L. (in press). The Prospective and Retrospective Memory Questionnaire (PRMQ): Normative data and latent structure in a large non-clinical sample. Memory.

Cutler, S. J., \& Grams, A. E. (1988). Correlates of self-reported everyday memory problems. Journal of Gerontology, 43, 82-90.

Dixon, R. A., \& BäckMAn, L. (1992). The concept of compensation in cognitive aging: The case of prose processing in adulthood. International Journal of Aging \& Human Development, 36, 199-217.

Dixon, R. A., \& Hultsch, D. F. (1983). Structure and development of metamemory in adulthood. Journal of Gerontology, 38, 682-688.

ERngrund, K., MäNTYLÄ, T., \& NiLsson, L.-G. (1996). Adult age differences in source memory: A population-based study. Journals of Gerontology: Psychological Sciences \& Social Sciences, 51, P335P345.

GLISKY, E. L. (1996). Prospective memory and frontal lobes. In M. A. Brandimonte, G. O. Einstein, \& M. A. McDaniel (Eds.), Prospective memory: Theory and applications (pp. 297-317). Hillsdale, NJ: Erlbaum.

Goschke, T., \& Kuhl, J. (1993). Representation of intentions: Persisting activation in memory. Journal of Experimental Psychology: Learning, Memory, \& Cognition, 19, 1211-1226.

Hashtroudi, S., Johnson, M. K., \& Chrosniak, L. D. (1989). Aging and source monitoring. Psychology \& Aging, 4, 106-112.

Herrmann, D. J. (1982). Know thy memory: The use of questionnaires to assess and study memory. Psychological Bulletin, 92, 434-452. 
Hertzog, C., Dixon, R. A., \& Hultsch, D. F. (1990). Metamemory in adulthood. In T. M. Hess (Ed.), Aging and cognition (pp. 161-212). Amsterdam: North-Holland.

Hertzog, C., Park, D., Morell, R. W., \& Martin, M. (2000). Behavioural specificity in the accuracy of subjective memory complaints. Applied Cognitive Psychology, 14, 257-275.

HuPPert, F. A., \& BeARdSAll, L. (1993). Prospective memory impairment as an early indicator of dementia. Journal of Clinical \& Experimental Neuropsychology, 15, 805-821.

Intons-Peterson, M. J. (1993). External memory aids and their relation to memory. In C. Izawa (Ed.), Memory improvement: Implications for memory theory (pp. 142-166). Hillsdale, NJ: Erlbaum.

Kahn, R. L., Zarit, S. H., Hilbert, N. M., \& Niederehe, G. (1975). Memory complaint and impairment in the aged: The effect of depression and altered brain function. Archives of General Psychiatry, 32, 1569-1573.

KAUSler, D. H. (1991). Experimental psychology, cognition, and human aging (2nd ed.). New York: Springer-Verlag.

Larrabee, G. J., \& Levin, H. S. (1986). Memory self-ratings and objective test performance in a normal elderly sample. Journal of Clinical \& Experimental Neuropsychology, 8, 274-284.

MÄNTY Lä, T. (1986). Optimizing cue effectiveness: Recall of 500 and 600 incidentally learned words. Journal of Experimental Psychology: Learning, Memory, \& Cognition, 12, 66-71.

MäntYlä, T. (1994). Remembering to remember: Adult age differences in prospective memory. Journals of Gerontology: Psychological Sciences \& Social Sciences, 49, P276-P282.

MÄNTY LÄ, T. (2000). Prospective remembering in adulthood: A longitudinal study. Paper presented at the 27th International Congress of Psychology, Stockholm.

MÄNTYLä, T., \& NILSSON, L.-G. (1997). Remembering to remember in adulthood: A population-based study. Aging, Neuropsychology, \& Cognition, 4, 81-92.

Mäntylä, T., \& SGaramella, T. (1997). Interrupting intentions: Zeigarnik-like effects in prospective memory. Psychological Research, 60, 192-199.

Marsh, R. L., Hicks, J. L., \& BinK, M. L. (1998). Activation of completed, uncompleted, and partially completed intentions. Journal of Experimental Psychology: Learning, Memory, \& Cognition, 24, 350-361.

Marsh, R. L., Hicks, J. L., \& LANdaU, J. D. (1998). An investigation of everyday prospective memory. Memory \& Cognition, 26, 633-643.

MAY LOR, E. A. (1990). Age and prospective memory. Quarterly Journal of Experimental Psychology, 42A, 471-493.

Maylor, E. A., Logie, B., Della Sala, S., \& Smith, J. (1996). The Prospective and Retrospective Memory Questionnaire (Tech. Rep. No. 132). University of Warwick.

McDaniel, M. A., Glisky, E. L., Rubin, S. R., Guynn, M. J., \& Routhieaux, B. C. (1999). Prospective memory: A neuropsychological study. Neuropsychology, 13, 103-110.

McGlone, J., Gupta, S., Humphrey, D., Oppenheimer, S., Missen, T., \& Evans, D. R. (1990). Screening for early dementia using memory complaints from patients and relatives. Archives of Neurology, 47, 1189-1193.

McIntyre, J. S., \& Craik, F. I. M. (1987). Age differences in memory for item and source information. Canadian Journal of Psychology, 41, 175-192.

Moscovitch, M. (1982). A neuropsychological approach to perception and memory in normal and pathological aging. In F. I. M. Craik \&
S. Trehub (Eds.), Aging and cognitive processes (pp. 55-78). New York: Plenum.

Nilsson, L.-G., Bäckman, L., ERngrund, K., Ny berg, L., Adolfsson, R., Bucht, G., Karlsson, S., Widing, M., \& Winblad, B. (1997). The Betula prospective cohort study: Memory, health, and aging. Aging, Neuropsychology, \& Cognition, 4, 1-32.

Nyberg, L., Bäckman, L., Erngrund, K., Olofsson, U., \& Nilsson, L.-G. (1996). Age differences in episodic memory, semantic memory, and priming: Relationships to demographic, intellectual, and biological factors. Journals of Gerontology: Psychological Sciences \& Social Sciences, 51, P234-P240.

Park, D., Hertzog, C., Leventhal, H., Morrell, R. W., Leventhal, E., Birchmore, D., Martin, M., \& Bennett, J. (1999). Medication adherence in rheumatoid arthritis patients: Older is wiser. Journal of the American Geriatric Society, 47, 172-183.

Poinrenaud, J., Malbezin, M., \& Guez, D. (1989). Self-rating and psychometric assessment of age-related changes in memory among young-elderly managers. Developmental Neuropsychology, 5, 285294.

Rabiitt, P. M. A., \& Abson, V. (1990). "Lost and found": Some logical and methodological limitations of self-report questionnaires as tools to study cognitive aging. British Journal of Psychology, 81, 1-16.

Reason, J. (1990). Human error. Cambridge: Cambridge University Press.

RIEGE, W. H. (1982). Self-report and tests of memory aging. Clinical Gerontology, 1, 23-36.

Scogin, F. (1985). Memory complaints and memory performance: The relationship re-examined. Journal of Applied Gerontology, 4, 79-89.

Shallice, T., \& Burgess, P. W. (1991). Deficits in strategy and application following frontal lobe damage in man. Brain, 114, 727-741.

Smith, G. E., Ivnik, R. J., Malec, J. F., \& Tangalos, E. G. (1993). Factor structure of the MOANS core battery: Replication in a clinical sample. Psychological Assessment, 5, 121-124.

Stuss, D. T., \& Benson, D. F. (1987). The frontal lobes and control of cognition and memory. In E. Pereceman (Ed.), The frontal lobes revisited (pp. 141-158). Hillsdale, NJ: Erlbaum.

Sunderland, A., Watts, K., Baddeley, A. D., \& Harris, J. E. (1986). Subjective memory assessment and test performance in elderly adults. Journal of Gerontology, 41, 376-384.

TAYlor, J. L., Miller, T. P., \& Tinklenberg, J. R. (1992). Correlates of memory declined: A 4-year longitudinal study of older adults with memory complaints. Psychology \& Aging, 7, 185-193.

TERRY, W. S. (1988). Everyday forgetting: Data from a diary study. Psychological Reports, 62, 299-303.

Tun, P. A., Perlmutter, L. C., Russo, P., \& Nathan, D. M. (1987). Memory self-assessment and performance in aged diabetics and nondiabetics. Experimental Aging Research, 13, 151-157.

West, R. L., BoAtwright, L. K., \& Schleser, R. (1984). The link between memory performance, self-assessment, and affective state. $E x$ perimental Aging Research, 10, 197-200.

Zelinski, E. M., Gilewski, M. J., \& Thompson, L. W. (1980). Do laboratory tests relate the self-assessment of memory ability in the young and old? In L. W. Poon, J. L. Fozard, L. S. Cermak, D. Arenberg, \& L. W. Thompson (Eds.), New directions in memory and aging (pp. 519-550). Hillsdale, NJ: Erlbaum.

(Manuscript received September 13, 1999; revision accepted for publication July 15, 2002.) 